\title{
Women with Mustaches and Men without Beards. Gender and Sexual Anxieties of Iranian Modernity. Berkeley - Los Angeles, University of California Press, 2005, 363 p.
}

\section{Azadeh Kian-Thiébaut}

\section{(2) OpenEdition}

\section{Journals}

Édition électronique

URL : http://journals.openedition.org/abstractairanica/20401

DOI : 10.4000/abstractairanica.20401

ISSN : 1961-960X

Éditeur :

CNRS (UMR 7528 Mondes iraniens et indiens), Éditions de l'IFRI

Édition imprimée

Date de publication : 15 mai 2007

ISSN : 0240-8910

\section{Référence électronique}

Azadeh Kian-Thiébaut, « Women with Mustaches and Men without Beards. Gender and Sexual Anxieties of Iranian Modernity. Berkeley - Los Angeles, University of California Press, 2005, 363 p. », Abstracta Iranica [En ligne], Volume 28 | 2007, document 404, mis en ligne le 18 septembre 2007, consulté le 25 septembre 2020. URL : http://journals.openedition.org/abstractairanica/20401 ; DOI : https://doi.org/10.4000/abstractairanica.20401

Ce document a été généré automatiquement le 25 septembre 2020.

Tous droits réservés 


\title{
Women with Mustaches and Men without Beards. Gender and Sexual Anxieties of Iranian Modernity. Berkeley - Los Angeles, University of California Press, 2005, 363 p.
}

\author{
Azadeh Kian-Thiébaut
}

1 L'intention de l'A., était d'écrire l'histoire de la modernité iranienne à travers l'usage analytique du genre afin que les questions relatives au genre et aux femmes ne soient plus marginales. Mais au fur et à mesure qu'elle écrivait sur le genre dans la formation de la modernité iranienne, elle a réalisé que penser le genre comme homme/femme est un impératif moderne rendu possible à travers l'effacement d'autres modes de masculinité : amrad (jeune adolescent) et moHannat (homme adulte, objet de désir pour les hommes). En incorporant une analyse critique de la définition homo/ hétérosexuelle, l'ouvrage devient une tentative remarquable de comprendre la culture moderne de l'Iran.

2 L'A. montre que l'Iran du XIX ${ }^{\mathrm{e}} \mathrm{s}$. a été structuré par la transformation du genre et de la sexualité. Les idées de la beauté dans l'Iran du XIX ${ }^{\mathrm{e}}$ s. n'étaient pas sexuées et le soleil sur le drapeau national (adopté officiellement en 1836) qui se lève derrière le buste d'un lion tenant une épée doit être vu comme un visage indifféremment féminin ou masculin. Dans le monde socio-culturel des Qajars, l'amour masculin était centré autour de l'homme aimé, mais, vers la fin du XIX ${ }^{\mathrm{e}}$ s., la modernité a considéré le désir homosexuel comme contre-nature, donnant pour responsables la réclusion des femmes et la ségrégation sexuelle. Plus tard, les femmes sont devenues plus visibles dans la société et la beauté s'est féminisée, le soleil symbole du drapeau national étant graduellement effacé car, d'une part, il consolidait son genre comme femelle, et d'autre part il était associé à la beauté de l'homme adolescent. Hétéronormalisation de l'éros et du sexe nécessitant l'hétérosocialisation de l'espace public et nouvelle configuration de 
la vie familiale sont devenues des conditions pour atteindre la modernité, tandis que l'homosexualité était désormais connotée comme arriérée. L'A. ne conteste pas l'idée que le genre et la sexualité aient généré le nationalisme moderne mais elle estime que l'hétéronormalisation de l'amour et de la sexualité doit aussi être vue comme l'œuvre du nationalisme et du patriotisme. L'image de l'Iran comme une femelle vénérée a consolidé l'amour hétérosexuel et a transformé le mariage d'un contrat de procréation en un contrat romantique. En revanche, la représentation de la mère patrie comme un corps malade et une figure féminine faible a offert au nationalisme le discours de la protection des femmes et de la défense de leur honneur, faisant de celles-ci des objets de possession et de protection par les hommes. Les modernistes, dont le projet était centré sur la loi, la science et le progrès, visaient la transformation du foyer à travers l'éducation des femmes et leur participation à la vie publique. La modernité iranienne, formée par la réarticulation de concepts tels que nation, politique, patrie et savoir, fut ainsi modelée comme un ordre patriarcal hétéronormalisé. Le patriotisme fut lié à la masculinité, les symboliques de l'État moderne iranien comme collectivité masculine ayant pour responsabilité la protection de la patrie femelle devinrent exclusivement masculines, de sorte que les revendications des femmes pour l'inclusion sociale et politique dans la famille nationale ne purent aboutir.

Dans l'épilogue, l'A. propose de lire le changement dans les sensibilités esthétiques (disparition de la moustache des femmes) non comme une tentative des Iraniennes pour ressembler aux Européennes mais plutôt comme la disparition de l'amrad de l'imagination culturelle et l'effacement de son importance pour la sexualité masculine.

4 A. Najmabadi a produit un ouvrage riche et original, qui contribue grandement à une meilleure compréhension de la culture moderne iranienne.

\section{INDEX}

Thèmes : 12.1. Iran

\section{AUTEURS}

\section{AZADEH KIAN-THIÉBAUT}

Université Paris VIII / Mondes iranien et indien 